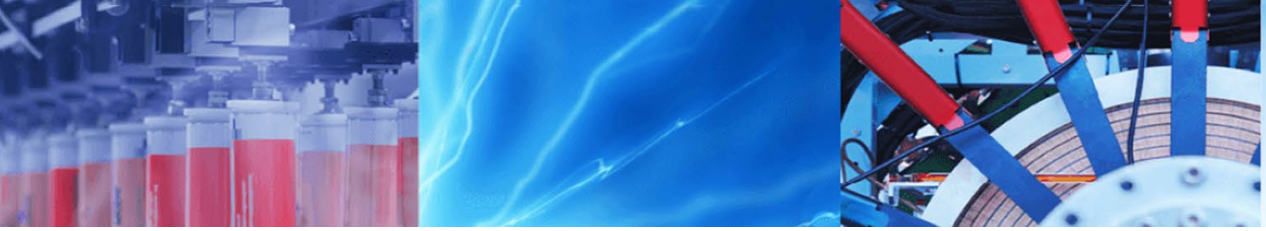

Research Article

\title{
Efficiency and economic optimization of shell and tube heat exchanger using bacteria foraging algorithm
}

\author{
Juluru Pavanu Sai ${ }^{1} \cdot$ B. Nageswara Rao ${ }^{1}$ (D)
}

Received: 30 October 2019 / Accepted: 26 November 2019 / Published online: 3 December 2019

(c) Springer Nature Switzerland AG 2019

\begin{abstract}
Shell and tube heat exchanger (STHE) is widely used in the industries for various purposes due to its capacity to withstand pressure. STHE has the drawback of more cost and lower efficiency. Many existing methods involve in applying the optimization technique to decrease the cost of the system. Existing method has the lower efficiency in the optimization due to the random initialization and poor convergence. This research applies the bacteria foraging algorithm (BFA) to increase the efficiency and decrease the cost of the STHE system. The BFA has the advantages of the faster convergence and the global search approach to increase the performance in design. The proposed BFA is evaluated in the two case studies and compared with the existing method. The proposed BFA in multi-objective optimization of STHE has the total cost of $41,464 €$, while existing method has the total cost of $41,913 €$. The proposed BFA method also achieved high heat efficiency coefficient of 1089, and the existing method has 1031.47 .
\end{abstract}

Keywords Bacteria foraging algorithm · Faster convergence · Global search approach · Shell and tube heat exchanger

$\begin{array}{ll}\text { List of symbols } \\ b & \text { Baffle spacing }(\mathrm{m}) \\ \mathrm{Cp} & \text { Specific heat }(\mathrm{kJ} / \mathrm{kg} \mathrm{K}) \\ C_{\text {inv }} & \text { Capital investment }(€) \\ \mathrm{CE} & \text { Energy cost }(€ / \mathrm{kWh}) \\ C_{\text {Annual }} & \text { Annual operating cost }(€ / \text { year }) \\ C_{\text {Total Disc }} & \text { Total discounted operating cost }(€) \\ C_{\text {total }} & \text { Total annual cost }(€) \\ d & \text { Tube diameter }(\mathrm{m}) \\ D & \text { Shell diameter }(\mathrm{m}) \\ f & \text { Friction factor } \\ F & \text { Correction factor } \\ h & \text { Heat transfer coefficient }\left(\mathrm{W} / \mathrm{m}^{2} \mathrm{~K}\right) \\ k & \text { Thermal conductivity }(\mathrm{W} / \mathrm{mK}) \\ L & \text { Tube length }(\mathrm{m}) \\ m & \text { Mass flow rate }(\mathrm{kg} / \mathrm{s}) \\ n_{\mathrm{t}} & \text { Number of tube passes } \\ n_{\mathrm{y}} & \text { Equipment life }(\mathrm{year}) \\ N_{\mathrm{t}} & \text { Number of tubes } \\ G & \text { Pumping power }(\mathrm{W})\end{array}$
$\operatorname{Pr} \quad$ Prandtl number
Pt Tube pitch (m)
$Q \quad$ Heat transfer rate (W)
Re Reynolds number
$\mathrm{RI} \quad$ Fouling resistance $\left(\mathrm{m}^{2} \mathrm{~K} / \mathrm{W}\right)$
$S \quad$ Heat transfer surface area $\left(\mathrm{m}^{2}\right)$
$T \quad$ Temperature (K)
$U \quad$ Overall heat transfer coefficient $\left(\mathrm{W} / \mathrm{m}^{2} \mathrm{~K}\right)$
$v \quad$ Fluid velocity $(\mathrm{m} / \mathrm{s})$

Greek symbols

$\Delta P \quad$ Pressure drop $(\mathrm{Pa})$

$\Delta T_{\mathrm{LM}} \quad$ Logarithmic mean temperature difference $\left({ }^{\circ} \mathrm{C}\right)$

$\mu \quad$ Dynamic viscosity (Pa s)

$\rho \quad$ Density $\left(\mathrm{kg} / \mathrm{m}^{3}\right)$

$\eta \quad$ Overall pumping efficiency

Subscripts

i Inlet

o Outlet

s Belonging to shell

B. Nageswara Rao, director_ies@vignan.ac.in; Juluru Pavanu Sai, Julurupavansai@gmail.com | 'Department of Mechanical Engineering, Vignan's Foundation for Science Technology \& Research, Vadlamudi, Guntur, Andhra Pradesh 522 213, India. 


$\begin{array}{ll}\mathrm{t} & \text { Belonging to the tube } \\ \mathrm{e} & \text { Equivalent } \\ \mathrm{w} & \text { Tube wall }\end{array}$

\section{Introduction}

Heat exchanger is core part in some industries like chemical industries, power plant, oil refining industries, etc. [1]. Traditional method in the STHE design applies the geometric assessment and operating constraints to select the design model [2]. The geometric feature of STHE and the fluid turbulence have impact on the exchanger efficiency [3]. Cost is the foremost objectives of the designers and industries to earn more profits [4]. Hence, the heat exchanger designing involves in investigating the geometric structure and operational parameter for improving thermal efficiency with cost constraint [5].

Proper design of the exchanger has impact on various aspects such as thermal stress, thermal drop, fluid dynamics properties, temperature, cleanability, fouling, and cost [6]. Experimental analysis of the heat exchanger involves in high cost and less flexibility for the analysis. Mathematical model of the heat exchanger in MATLAB tool helps to analyze the exchanger more flexible with less cost. Evolutionary algorithms have been applied by various researchers to optimize the design to increase the efficiency and reduce the cost. These methods solve the problems of multi-modality, nonlinearity, and noncontinuity, in which conventional methods found difficulty to solve [7]. Many optimization methods including particle swarm optimization (PSO) have been used to solve the optimization problem in design of STHE and found to have considerable performance for the method [8,9]. Multi-objective optimization techniques were used to improve the design with the objective of both economic and efficiency [10]. In this research, the multi-objective optimization of BFA is used for the STHE with various parameter designs. The BFA has the advantages of faster convergence and the global search method to increase the performance. The simulation result shows that the BFA has the higher performance compared to existing method. The proposed BFA method has the advantages of the fast convergence and global search for the optimal solution of the design. The proposed BFA design provides the total cost of $41,464 €$, and existing method has the total cost of $41,913 €$. The heat efficiency of the BFA method is high compared to the other existing method due to its optimal design of the system.

The paper is formulated as the literature survey of optimization of STHE is given in Sect. 2, the explanation about the performance of BFA is given in Sect. 3, STHE simulation results are briefly explained in Sect. 4 , and Sect. 5 contains conclusion.

\section{Literature survey}

The STHE is used in the industries for the heat transfer, and this can withstand more pressure compared to other exchanger types. Various optimization techniques were applied in the STHE to increase the efficiency. The optimization techniques applied in the STHE with considerable performance were surveyed in this section.

Caputo et al. [11] applied the genetic algorithm (GA) for economic optimization of the STHE design. The GA method reduces the total cost and maintains system cost of pumping. The three case studies were used to analyze the performance of the GA method in terms of cost. The result shows that the GA method significantly reduces the cost of the system and increases the performance. The GA is depending on the initial population, and this affects the performance of the optimization.

Patel and Rao [12] established PSO for the STHE economic optimization of design, and the three design variables were used for the STHE optimization. The method is tested on the two different tube layouts for the analysis. The developed method is evaluated in four case studies to analyze the efficiency and accuracy. The result shows that the performance of PSO is higher than the GA in economic optimization of the STHE. Multi-objective optimization needs to be considered in this method for increasing the efficiency.

Sahin et al. [13] established the artificial bee colony (ABC) method for the economic optimization of the STHE design. Various designs like tube length, baffle spacing, etc., were considered in the optimization. The three case studies were used to analyze the efficiency of the $A B C$ in optimization. The experimental result shows that the performance of the developed method is high compared to existing method in optimization technique. The developed method does not effectively analyze the design in the system. The efficiency of the heat exchange is affected and has the lower convergence in the process.

Hadidi and Nazari [14] developed biogeographybased optimization (BBO) for economic optimization of the STHE. There are various designs like tube length and baffle spacing, etc., and variables are considered in the optimization technique. The developed method is tested on the three case studies to analyze the performance. The developed method has the high performance compared to the existing technique in STHE economic optimization. The multi-objective optimization is required to be processed. This method has the 
poor convergence, and the search process needs to be improved.

lyer et al. [15] developed adaptive range genetic algorithm (ARGA), and the GA is combined with the cohort intelligence $(\mathrm{Cl})$ to utilize the sample space reduction. The correctness of ARGA is tested on the 50 standard test function. Various designs are used for the optimization of the STHE. The three case studies were used to evaluate the efficiency of the ARGA method. The simulation results show that the ARGA method has the higher performance compared to the existing method. The developed method is depending on the initial population, and this affects the performance of the optimization.

In order to overcome the above limitation of the existing method, the BFA method is proposed in the STHE optimization. The proposed BFA has the advantages of faster convergence and the global search method to increase the performance.

\section{Proposed method}

The several optimization techniques were applied in the multi-objective STHE design to increase the efficiency and decrease the cost. Existing method has the lower efficiency in the exchanger and more cost due to the design. In this research, BFA is proposed for the optimization in STHE design. Various designs are considered for the optimization process, and two case studies were used to analyze the BFA method efficiency. The general block diagram of BFA in STHE design is shown in Fig. 1.

\subsection{Heat exchanger design formulation}

Mathematical model of the STHE is discussed in this subsection. STHE is modeled in MATLAB based on mathematical expressions. The surface area $(S)$ was calculated as based on Eq. (1)

$S=\frac{Q}{U \Delta T_{\mathrm{LM}} F}, F=$ correction factor

where heat transfer rate is represented by $Q, \Delta T_{\mathrm{LM}}$ represents the temperature difference logarithmic mean of counter flow, and $U$ represents overall heat transfer coefficient (HTC).

The $U$ depends on heat transfer coefficient of shell and tube side and fouling resistance [16]. This is measured based on Eq. (2)

$U=\frac{1}{\frac{1}{h_{s}}+R_{l s}+\frac{d_{0}}{d_{i}}\left(R_{/ t}+\frac{1}{h_{t}}\right)}$

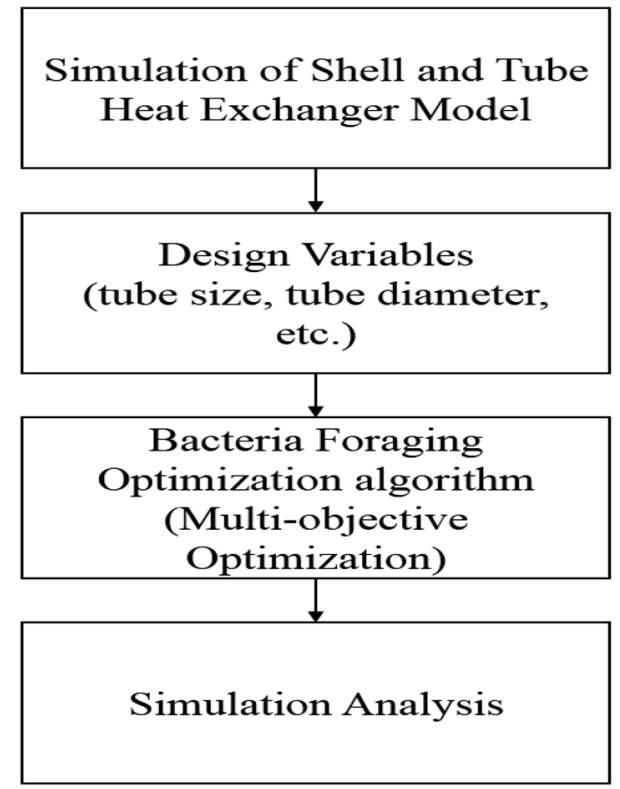

Fig. 1 The proposed BFA in STHE design block diagram

where $d_{i}=0.8 d_{a}$.

The shell-side HTC $h_{s}$ is measured based on the segmental baffle of exchanger, denoted in Eq. (3).

$h_{s}=0.36 \frac{k_{s}}{D_{e}} \operatorname{Re}_{s}^{0.55} \operatorname{Pr}_{s}^{\frac{1}{3}}\left(\frac{\mu_{s}}{\mu_{w}}\right)^{0.14}$

The tube-side heat transfer coefficient $h_{t}$ is measured using Eq. (4).

$$
\begin{aligned}
h_{t}= & \frac{k_{t}}{d_{i}}\left\{\frac{f_{t}\left(\operatorname{Re}_{t}-1000\right) \operatorname{Pr}_{t}}{1+12.7 \sqrt{\frac{f_{t}}{8}}\left(\operatorname{Pr}_{t}^{\frac{2}{3}}-1\right)}\left[1+\left(\frac{d_{i}}{L}\right)^{0.67}\right]\right\} \\
& \times\left(2300<\operatorname{Re}_{t}<10,000\right)
\end{aligned}
$$

Considering the cross-flow of adjacent baffle with $\Delta T_{\mathrm{LM}}$, measured using Eq. (5).

$\Delta T_{\mathrm{LM}}=\frac{\left(T_{\text {is }}-T_{\text {ot }}\right)-\left(T_{\text {os }}-T_{i t}\right)}{\ln \left[\frac{T_{i s}-T_{\text {ot }}}{T_{\text {os }}-T_{\text {it }}}\right]}$

\subsection{Bacteria foraging optimization algorithm}

The BFA is optimization technique inspired from the e-coli bacteria foraging group method. Tensile flagella move the bacteria in particular direction, and in foraging, this performs tumble and swing. The bacteria rotate its flagella, and then 
bacterium tumbles to move in a nutrient gradient. The BFA method has the advantages of fast convergence in the process. Based on the inspiration of this process, e-coli bacteria phenomena [16] are developed with four steps. These four methods are discussed as follows.

\subsubsection{Chemotaxis}

The swimming and tumbling process is carried out in this step to enable the bacteria to move.

Assume that $\theta_{i}(j, k, I)$ denotes the $i$ th bacterium position at $j$ th chemotactic, with /th elimination-dispersal step and $k$ th reproduction. The swimming and tumbling of the movement of bacteria can be represented in Eq. (6)

$\theta_{i}(j+1, k, l)=\theta_{i}(j, k, l)+C(i) \frac{\Delta(i)}{\Delta T(i) \Delta(i)}$

where $\theta_{i}$ denotes the objective function, and $C(i)$ represents the tumble taken step size in random direction. The vector in the random direction is denoted as $\Delta$ whose elements are present between $[-1,1]$.

\subsubsection{Swarming}

The repellents and attractants were released in this step by e-coli cells to communicate with other cells. This step avoids noxious environments and combines into groups in rich nutrient environment. The cell-to-cell signaling equation is represented as given in Eq. (7)

$$
\begin{aligned}
& J_{C C}(\theta, P(j, k, I))=\sum_{i=1}^{s} J_{C C}\left(\theta, \theta^{i}(j, k, I)\right) \\
& =\sum_{i=1}^{s}\left[-d_{\text {attractant }} \exp \left(-w_{\text {repellent }} \sum_{m=1}^{P}\left(\theta_{m}-\theta_{m}^{i}\right)^{2}\right)\right]
\end{aligned}
$$

where $J_{C C}(\theta, P(j, k, l))$ is the additional part with actual objective function with $S$ denoting the total number of bacteria and $p$ is the number of factors in search space, $\theta=\left[\theta_{1}, \theta_{2}, \ldots, \theta_{p}\right]_{T}$ denote the location of the search space and $\theta$ mis denotes the $m$ th components of the $i$ th bacterium position $\theta_{i}$, and different coefficients are used for signaling.

\subsubsection{Reproduction}

The least health bacteria die in this $\operatorname{step}\left(S_{r}=S / 2\right)$, and healthier bacteria are divided into two bacteria that are present in this vacant location.

\subsubsection{Elimination-dispersal}

The bacteria life may be affected due to change in the environment. To denote this process, each bacterium in population is eliminated based on probability $P_{\text {ed }}$ and a new replacement is initialized randomly.

The part sequence matrix is used to denote the position of each bacterium, and pairwise interchange mutation is applied to find each bacterium movement during swimming and tumbling process. The bacteria position is updated in swimming and tumbling of chemotaxis as follows in Eq. (8)

$\theta_{i}=(j+1, k, l)=f_{1}\left(C, \theta_{i}(j, k, l)\right)$

where $f_{1}$ denotes the mutation operation, and the number of random pairwise interchange is denoted as $C$ for each mutation operation.

The optimized design provided by the BFA is evaluated in the heat exchanger simulation model, and various aspects are analyzed. The simulation result of the proposed BFA in multi-objective optimization of the STHE is discussed.

\section{Simulation result}

This research involves in applying the BFA method in the design of STHE for the multi-objective optimization. The proposed BFA is tested on the two case studies with various design parameters, and aspects are calculated. The cost measurement and the design of the case studies are based on the analysis used in research [15]. The proposed BFA is tested on the MATLAB installed in the system of Intel core i7 processor with $8 \mathrm{~GB}$ of RAM. Table 1 shows the details of the case study. The number of bacteria is set as 20 , the number of chemotaxis steps is set as 2 , the number of reproduction step is set as 100 , and the number of swarming steps is set as 10 .

Table 1 Case study details

\begin{tabular}{ll}
\hline Case study 1 & Case study 2 \\
\hline $4.34(\mathrm{MW})$ heat duty, methanol-brackish water heat exchanger & $1.44(\mathrm{MW})$ heat duty, kerosene-crude oil heat exchanger
\end{tabular}


Table 2 Performance analysis of case study 1

\begin{tabular}{|c|c|c|c|}
\hline Parameters & BBO [14] & ARGA [15] & BFA \\
\hline$D_{s}(\mathrm{~m})$ & 0.801 & 0.665 & 0.675 \\
\hline$L(\mathrm{~m})$ & 2.04 & 1.263 & 1.52 \\
\hline$b(\mathrm{~m})$ & 0.5 & 0.49 & 0.47 \\
\hline$d_{0}(\mathrm{~m})$ & 0.01 & 0.01 & 0.01 \\
\hline$P_{t}(\mathrm{~m})$ & 0.0125 & 0.012 & 0.012 \\
\hline$C_{l}(\mathrm{~m})$ & 0.0025 & 0.002 & 0.002 \\
\hline$n_{t}$ & 2 & 2 & 2 \\
\hline$N_{t}$ & 3587 & 2625.87 & 2461.52 \\
\hline$v_{t}(\mathrm{~m} / \mathrm{s})$ & 0.77 & 1.049 & 1.053 \\
\hline $\operatorname{Re}_{t}$ & 7642.4 & $10,440.1$ & 11,212 \\
\hline $\mathrm{Pr}_{t}$ & 5.7 & 5.694 & 5.682 \\
\hline$h_{t}\left(\mathrm{~W} / \mathrm{m}^{2} \mathrm{~K}\right)$ & 4314 & 6196 & 6203 \\
\hline$f_{t}$ & 0.034 & 0.031 & 0.33 \\
\hline$\Delta P_{t}(\mathrm{~Pa})$ & 6156 & 9756.24 & 9821.26 \\
\hline$a_{s}\left(\mathrm{~m}^{2}\right)$ & 0.0801 & 0.065 & 0.0735 \\
\hline$D_{e}(\mathrm{~m})$ & 0.007 & 0.007 & 0.007 \\
\hline$v_{s}(\mathrm{~m} / \mathrm{s})$ & 0.46 & 0.568 & 0.524 \\
\hline $\operatorname{Re}_{s}$ & 7254 & 8912.33 & 7826 \\
\hline $\mathrm{Pr}_{s}$ & 5.1 & 5.082 & 5.103 \\
\hline$h_{s}\left(\mathrm{~W} / \mathrm{m}^{2} \mathrm{~K}\right)$ & 2197 & 2422.8 & 2512.7 \\
\hline$f_{s}$ & 0.379 & 0.368 & 0.374 \\
\hline$\Delta P_{s}(\mathrm{~Pa})$ & 13,799 & $10,746.3$ & $11,213.2$ \\
\hline$U\left(\mathrm{~W} / \mathrm{m}^{2} \mathrm{~K}\right)$ & 755 & 1031.47 & 1089 \\
\hline$S\left(m^{2}\right)$ & 229.95 & 168.275 & 172.14 \\
\hline$C_{\text {inv }}(€)$ & 44,536 & $35,498.9$ & 34,228 \\
\hline$C_{\text {annual }}(€ /$ year $)$ & 984 & 1043.96 & 1024 \\
\hline$C_{\text {total }}(€)$ & 6046 & 6414.68 & 6212 \\
\hline$C_{\text {total }}(€)$ & 50,582 & $41,913.5$ & 41,464 \\
\hline
\end{tabular}

\subsection{Performance analysis on case 1}

The performance of proposed BFA in the multi-objective optimization of the STHE in case study 1 is shown in Table 2. Various parameters are analyzed in the method and have the optimal value for the parameter settings. The existing optimization method in the design of the heat exchanger is used to compare with the proposed BFA method to analyze the performance.

The simulation result of proposed BFA in the optimization of the STHE is shown in Table 2. The experimental result shows that the proposed BFA has the higher performance than the other existing methods. The proposed BFA has the lower cost compared to the other optimization technique. The optimal value of the BFA is shown in Table 2 to increase the efficiency and decrease the cost. The proposed BFA has the total cost value of $41,464 €$ compared to the existing method of ARGA that has the total cost value of $41,913 €$. The proposed method has the advantages of the fast convergence and global search for optimal solution that helps to provide better performance. The proposed BFA method is various parameters to find the optimal design specification for multi-objective optimization. The heat transfer coefficient and the total cost of the heat exchanger are two important parameters considered for the optimization. The length of the tube is the important parameter that increases the flow and heat transfer in the tube side. The number of tubes is reduced to decrease the cost, and also heat transfer rate of efficiency is maintained by the design of the heat exchanger.

The capital cost and total discount operating cost are compared with the existing method, as shown in
Fig. 2 The total cost of the proposed method

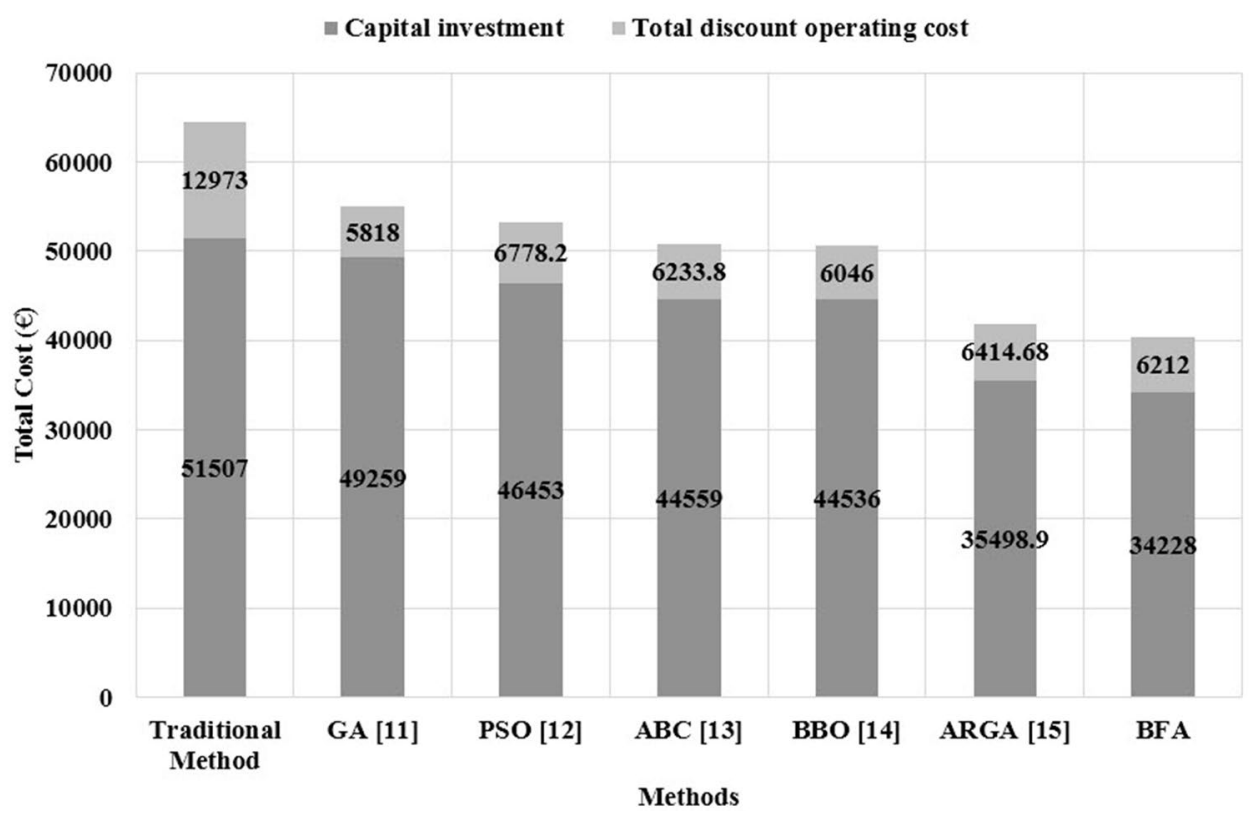


Table 3 Performance analysis of case study 2

\begin{tabular}{|c|c|c|c|}
\hline Parameters & BBO [14] & ARGA [15] & BFA \\
\hline$D_{s}(\mathrm{~m})$ & 0.74 & 0.4 & 0.4 \\
\hline$L(\mathrm{~m})$ & 1.199 & 0.71 & 0.72 \\
\hline$b(\mathrm{~m})$ & 0.1066 & 0.154 & 0.132 \\
\hline$d_{0}(\mathrm{~m})$ & 0.015 & 0.011 & 0.012 \\
\hline$P_{t}(\mathrm{~m})$ & 0.0188 & 0.014 & 0.013 \\
\hline$C_{l}(\mathrm{~m})$ & 0.0038 & 0.002 & 0.002 \\
\hline$n_{t}$ & 2 & 2 & 2 \\
\hline$N_{t}$ & 1061 & 635.229 & 652.124 \\
\hline$v_{t}(\mathrm{~m} / \mathrm{s})$ & 0.69 & 0.904 & 0.822 \\
\hline $\operatorname{Re}_{t}$ & 2298 & 2300 & 2300 \\
\hline $\operatorname{Pr}_{t}$ & 55.2 & 56.453 & 57.52 \\
\hline$h_{t}\left(\mathrm{~W} / \mathrm{m}^{2} \mathrm{~K}\right)$ & 1251 & 1174.57 & 1263 \\
\hline$f_{t}$ & 0.05 & 0.049 & 0.05 \\
\hline$\Delta P_{t}(\mathrm{~Pa})$ & 5109 & 5179.41 & 5189.73 \\
\hline$a_{s}\left(\mathrm{~m}^{2}\right)$ & 0.0158 & 0.012 & 0.012 \\
\hline$D_{e}(\mathrm{~m})$ & 0.0149 & 0.008 & 0.008 \\
\hline$v_{s}(\mathrm{~m} / \mathrm{s})$ & 0.432 & 0.524 & 0.562 \\
\hline $\operatorname{Re}_{s}$ & 13,689 & 9073.64 & 9082.14 \\
\hline $\operatorname{Pr}_{s}$ & 7.5 & 7.6 & 7.6 \\
\hline$h_{s}\left(\mathrm{~W} / \mathrm{m}^{2} \mathrm{~K}\right)$ & 1278 & 1857.58 & 1872 \\
\hline$f_{s}$ & 0.345 & 0.367 & 0.372 \\
\hline$\Delta P_{s}(\mathrm{~Pa})$ & 15,275 & 9708 & 9827 \\
\hline$U\left(\mathrm{~W} / \mathrm{m}^{2} \mathrm{~K}\right)$ & 317.75 & 336.128 & 321.26 \\
\hline$S\left(m^{2}\right)$ & 60.35 & 56.84 & 62.12 \\
\hline$C_{\text {inv }}(€)$ & 18,799 & $18,241.8$ & $18,132.7$ \\
\hline$C_{\text {annual }}(€ /$ year $)$ & 164.414 & 155.71 & 155.82 \\
\hline$C_{\text {total }_{\text {disc }}}(€)$ & 1010.25 & 956.79 & 937.84 \\
\hline$C_{\text {total }}(€)$ & 19,810 & $19,198.6$ & 18,824 \\
\hline
\end{tabular}

Fig. 2. The proposed method has lower capital cost due to the minimization of the requirement in the manufacturing. The proposed method total cost is lower cost due to reduction of capital cost. The total cost of the proposed method design is low, and this is due to fast convergence and global search process of the proposed BFA method. The number of tubes is reduced in the proposed BFA design that majorly helps to reduce the cost of the exchanger.

\subsection{Performance analysis on case 2}

The proposed BFA is tested on case study 2 to analyze the performance, as shown in Table 3. Various design parameters are analyzed in the method for the optimum performance.

The proposed BFA is tested on case study 2 with different parameters and compared with the existing method, as shown in Table 3. This shows that the proposed BFA has higher performance compared to other existing methods in STHE optimization. The BFA method has fast convergence in the search process and able to analyze various parameters. This helps to find the optimal design for the heat exchanger with low cost and high efficiency. The proposed method decreases the cost compared to the other existing method in STHE. The total cost of BFA method is $18,824 €$ compared to the existing ARGA method that has the cost of $19,198.6 €$. The length of the tube and the number of tubes are increased by the proposed BFA design that helps to increase the heat transfer coefficient than the existing method.
Fig. 3 The total discount operating cost and capital investment

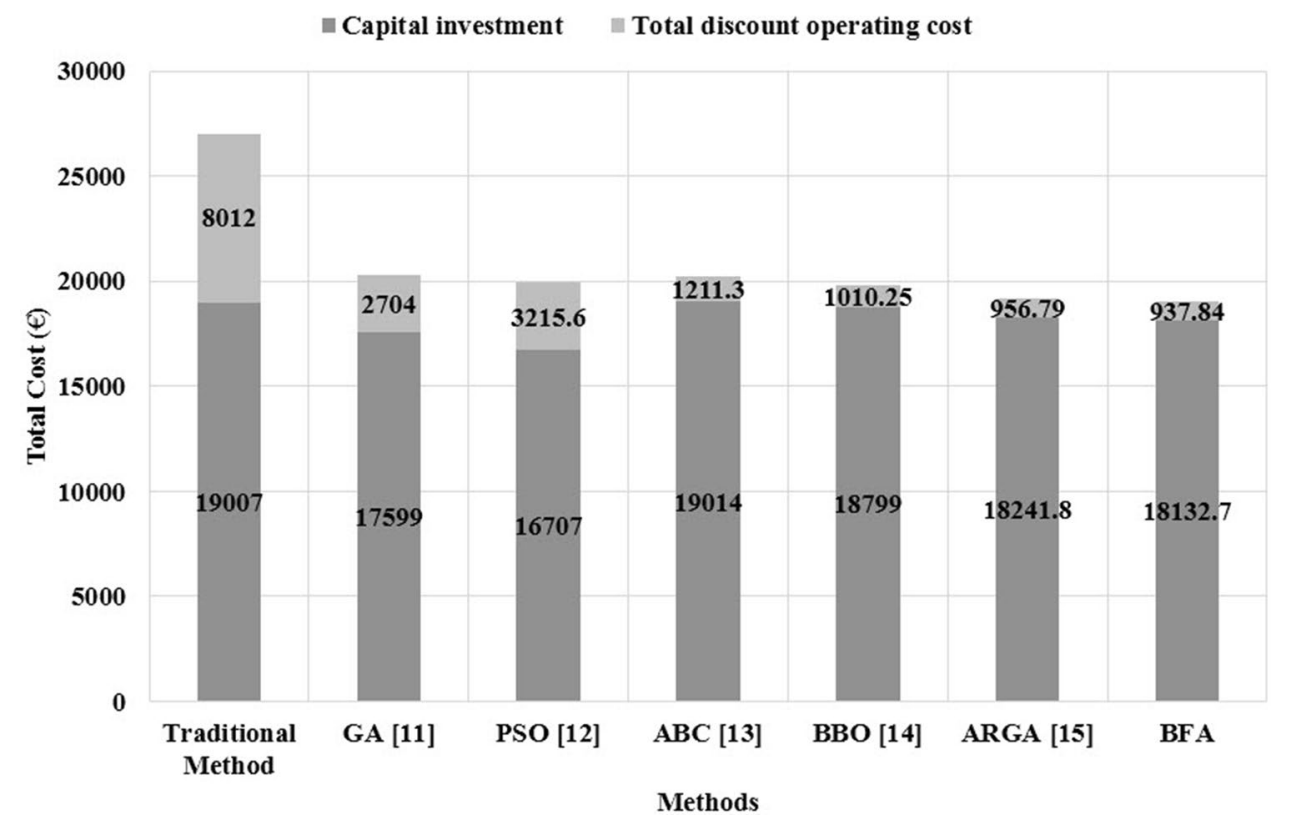


The proposed BFA method of total discount operating cost and capital investment is shown in Fig. 3. This shows that the total cost of the proposed BFA design is lower than other existing methods. The proposed BFA method has the capital investment of $18,132 €$, while existing method has the capital investment of $18,241.8 €$. The proposed method decreases the total cost of the heat exchanger without affecting heat transfer efficiency of the system.

The proposed BFA has the higher performance in the economic design of the STHE system. The proposed BFA increases the efficiency of the method and decrease the cost of the system. Therefore, the proposed BFA method has a higher performance in the heat transfer efficiency and economic optimization of the design.

\section{Conclusion}

The cost of STHE is high, and the efficiency needs to be increased by applying the optimal design. Many existing methods are applied in the optimization of the STHE system to decrease the cost. In this research, BFA is applied to increase the performance and decrease the system cost. The proposed BFA method is evaluated on the two case studies and compared with the existing method to analyze the performance. The simulation result shows that the proposed BFA has the higher efficiency and lower cost for the STHE. The proposed BFA has the cost value of $18,824 €$, while existing method ARGA method has the cost value of $19,198.6 €$. The proposed BFA method has a heat transfer coefficient of 1089, while existing method has 1031.47. The proposed BFA method decreases the total cost of the heat exchanger and also increase the efficiency. In the both test case analysis, the proposed BFA method shows the lower cost in the design and high efficiency. The future work of this method involves in analyzing the different baffle cut designs for the STHE to increase the efficiency of the system.

\section{Compliance with ethical standards}

Conflict of interest The authors declare that they have no conflict of interest.

\section{References}

1. Arani AAA, Moradi R (2019) Shell and tube heat exchanger optimization using new baffle and tube configuration. Appl Therm Eng 157:113736

2. Rodríguez MBR, Rodríguez JLM, Fontes CHDO (2019) Thermo ecological optimization of shell and tube heat exchangers using NSGA II. Appl Therm Eng 156:91-98

3. Roy U, Pant HK, Majumder M (2018) Detection of significant parameters for shell and tube heat exchanger using polynomial neural network approach. Vacuum 166:399-404

4. Roy U, Majumder M (2019) Economic optimization and energy analysis in shell and tube heat exchanger by meta-heuristic approach. Vacuum 166:413-418

5. Rao RV, Saroj A (2017) Economic optimization of shell-and-tube heat exchanger using Jaya algorithm with maintenance consideration. Appl Therm Eng 116:473-487

6. Rao RV, Saroj A (2017) Constrained economic optimization of shell-and-tube heat exchangers using elitist-Jaya algorithm. Energy 128:785-800

7. de Vasconcelos Segundo EH, Amoroso AL, Mariani VC, dos Santos CL (2017) Economic optimization design for shell-and-tube heat exchangers by a Tsallis differential evolution. Appl Therm Eng 1111:143-151

8. Raja BD, Jhala RL, Patel V (2017) Many-objective optimization of shell and tube heat exchanger. Therm Sci Eng Prog 2:87-101

9. Azarkish H, Rashki M (2019) Reliability and reliability-based sensitivity analysis of shell and tube heat exchangers using Monte Carlo simulation. Appl Therm Eng 1591:13842

10. Mohanty DK (2016) Gravitational search algorithm for economic optimization design of a shell and tube heat exchanger. Appl Therm Eng 107:184-193

11. Caputo AC, Pelagagge PM, Salini P (2008) Heat exchanger design based on economic optimisation. Appl Therm Eng 28:1151-1159

12. Patel VK, Rao RV (2010) Design optimization of shell-and-tube heat exchanger using particle swarm optimization technique. Appl Therm Eng 30:1417-1425

13. Şahin AŞ, Kılıç B, Kılıç U (2011) Design and economic optimization of shell and tube heat exchangers sing Artificial Bee Colony (ABC) algorithm. Energy Convers Manag 52:3356-3362

14. Hadidi A, Nazari A (2013) Design and economic optimization of shell-and-tube heat exchangers using biogeography-based (BBO) algorithm. Appl Therm Eng 51:1263-1272

15. Iyer VH, Mahesh S, Malpani R, Sapre M, Kulkarni AJ (2019) Adaptive range genetic algorithm: a hybrid optimization approach and its application in the design and economic optimization of shell-and-tube heat exchanger. Eng Appl Artif Intell 85:444-461

16. Majumder A, Laha D (2017) Bacteria foraging optimization algorithm for robotic cell scheduling problem. Mater Today Proc 4:2129-2136

Publisher's Note Springer Nature remains neutral with regard to jurisdictional claims in published maps and institutional affiliations. 